\title{
Factors associated with persistent atrial fibrillation after achievement of euthyroid state
}

\author{
A. Melki, M. Yazidi, I. Barka, F. Chaker, M. Chihaoui, O. Rejeb, H. Slimane \\ Department of Endocrinology- The Rabta hospital
}

\section{INTRODUCTION}

Atrial fibrillation (AF) occurs in up to $15 \%$ of patients with hyperthyroidism. Although hyperthyroidism is usually regarded as a reversible cause of $A F$, spontaneous sinus conversion occurs in only $2 / 3$ of patients upon the normalization of T4 levels.

The aim of this study was to identify factors associated with persistent atrial fibrillation after restoration of euthyroid state.

\section{METHODS}

Retrospective study of 13 years.

$\square$ Twenty patients hospitalized for hyperthyroidism with AF and who had normalized their FT4 level during follow-up were enrolled.

$\square$ Non parametric Mann Whitney test was used to compare medians.

\section{RESULTS}

The median follow-up period was 58 months.

At the end of the follow-up period, 6 patients were euthyroid, 13 hypothyroid and 1 patient had a subclinical hyperthyroidism.

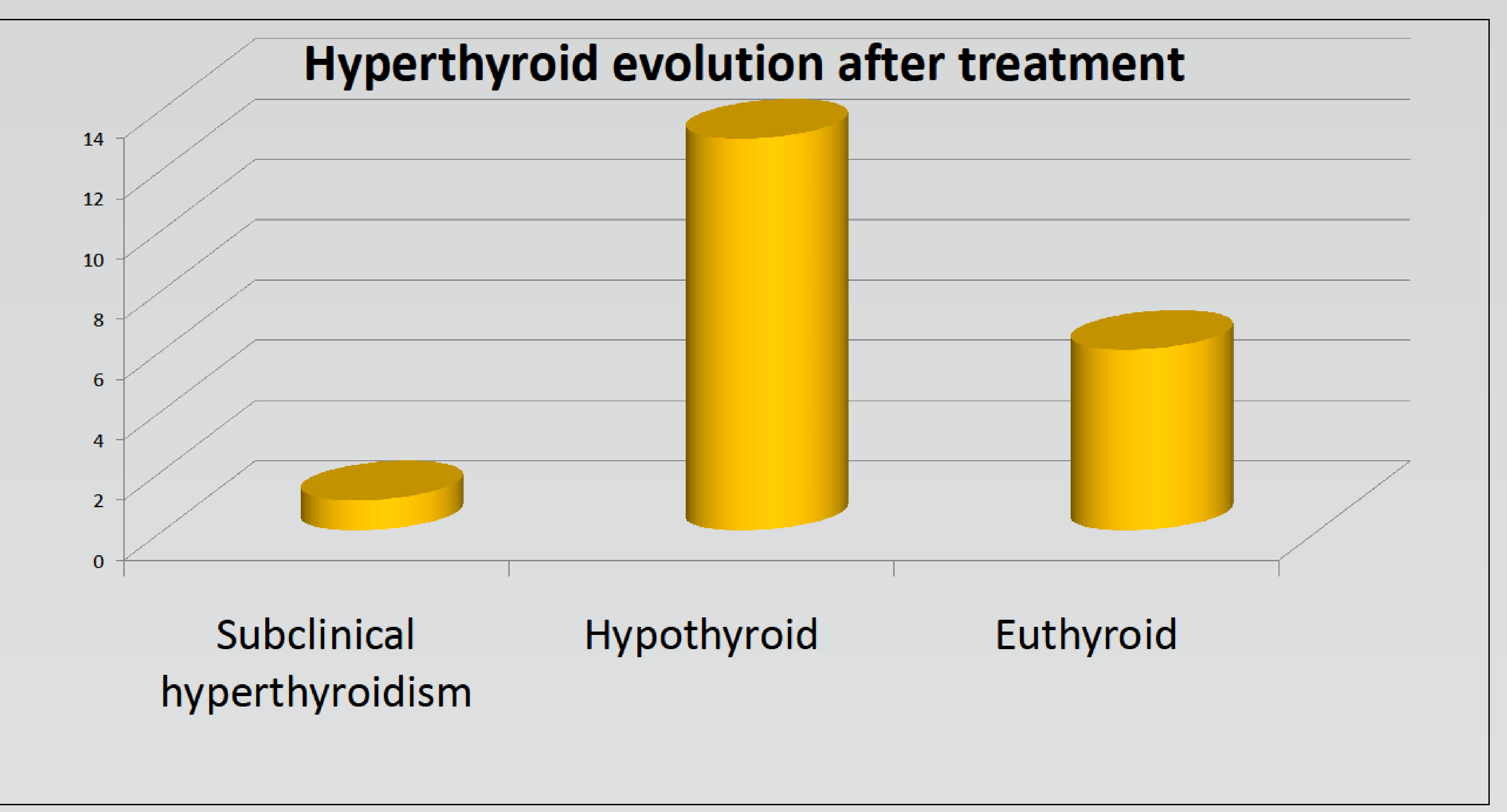

Eight of the 20 patients returned to sinus rhythm after a median of 15 months.

Evolution of AF after normalization of T4 level

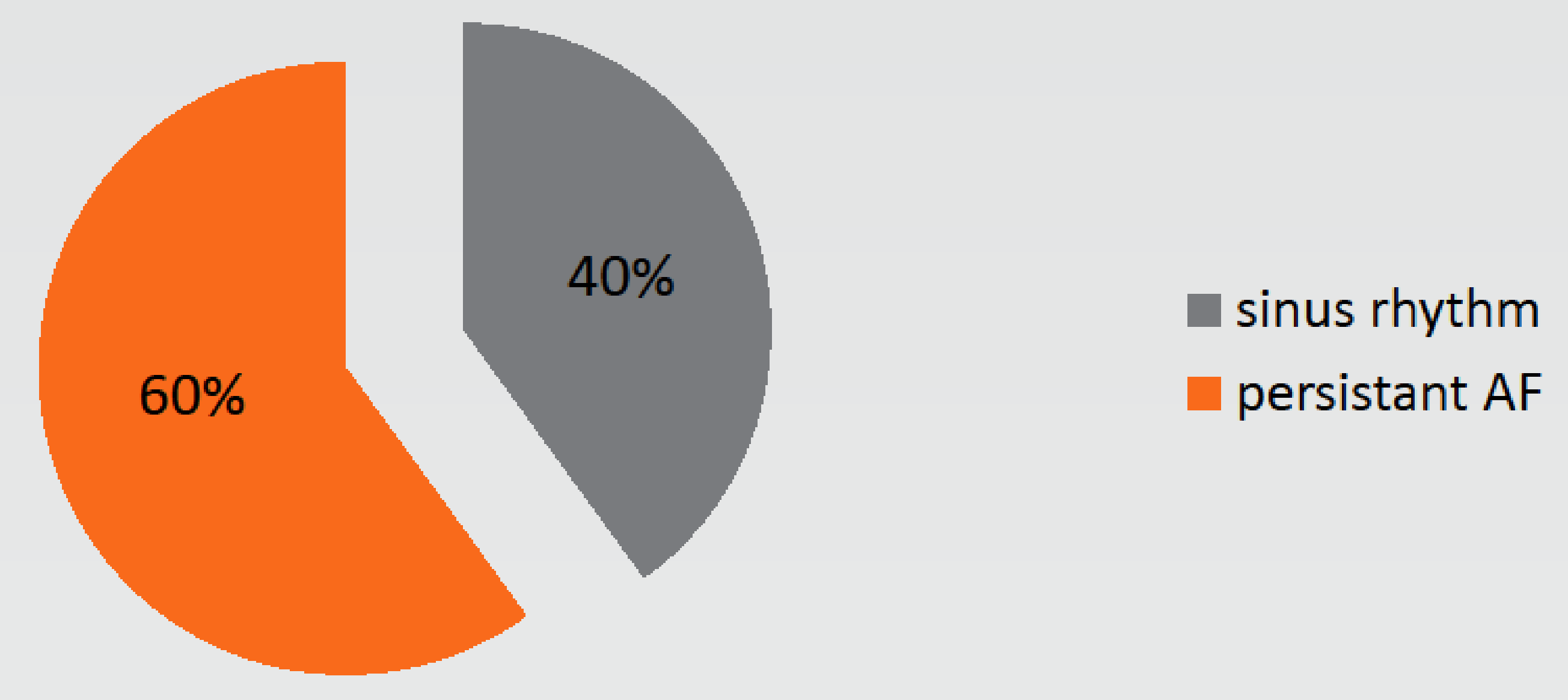

$\square$ We found no significant difference between subjects who returned to sinus rhythm and those with persistent $A F$ in terms of:

\begin{tabular}{|c|c|c|}
\hline $\begin{array}{l}\text { Patients } \\
\text { who } \\
\text { returned to } \\
\text { sinus } \\
\text { rhythm }\end{array}$ & $\begin{array}{l}\text { Patients } \\
\text { with } \\
\text { persistent } \\
\text { AF }\end{array}$ & $p$ \\
\hline $55,3 \pm 18,6$ & $55,9 \pm 12,3$ & 1 \\
\hline $58,3 \%$ & $41,7 \%$ & 0,65 \\
\hline $25 \%$ & $25 \%$ & 1 \\
\hline $12,5 \%$ & $16,7 \%$ & 1 \\
\hline $33,3 \%$ & $10 \%$ & 0,51 \\
\hline $55,1 \pm 13,2 \%$ & $59 \pm 5 \%$ & 0,71 \\
\hline $16,7 \%$ & $83,3 \%$ & 0,33 \\
\hline $3,5 \pm 0,8$ & $5,1 \pm 5,1$ & 0,77 \\
\hline $29,1 \pm 48,2$ & $31,9 \pm 27,6$ & 0,17 \\
\hline
\end{tabular}

\section{DISCUSSION AND CONCLUSION}

-Successful treatment of hyperthyroidism resulted in conversion from atrial fibrillation in up to one third of our patients.

- INakazawa HK et al indicated that $62 \%$ of atrial fibrillation reverted to sinus rhythm within the first 3 to 4 months after the control of thyrotoxicosis, even without antiarrhythmic therapy.

-This study suggests that spontaneous reversion of atrial fibrillation to sinus rhythm is highly unlikely if the duration of atrial fibrillation before the achievment of euthyroid state exceeds 13 months - In our study, no factors were associated with persistent atrial fibrillation. 